\title{
MANDRÁGORA: A HISTÓRIA DE UM OUSADO PERIÓDICO FEMINISTA NA ÁREA DE CIÊNCIAS DA RELIGIÃO E TEOLOGIA
}

\author{
Sandra Duarte de Souza*
}

RESUMO

O artigo apresenta o contexto do surgimento da Mandrágora, Revista de Estudos de Gênero e Religião do Programa de Pós-Graduação em Ciências da Religião da Universidade Metodista de São Paulo. Os objetivos são vários: contar a história da criação do NETMAL - Núcleo de Estudos Teológicos da Mulher na América Latina, em 1989, por iniciativa de estudantes do Programa de Pós-Graduação em Ciências da Religião; pontuar a importância do grupo para a presença e permanência de docentes feministas no Programa; destacar a produção de gênero do PPG na forma de teses e dissertações; e demonstrar que o mais antigo periódico de gênero e religião do Brasil é parte de um longo processo de trabalho de reflexão e ação feminista no campo dos Estudos de Religião.

Palavras-chave: Mandrágora; Estudos Feministas; Gênero; Ciências da Religião; Teologia

\section{MANDRÁGORA: THE STORY OF A BOLD FEMINIST JOURNAL IN THE AREA OF SCIENCES OF RELIGION AND THEOLOGY}

\section{ABSTRACT}

The article presents the context of the emergence of Mandrágora, Journal on Gender and Religion Studies of the Graduate Program in Sciences of Religion at the Methodist University of São Paulo. The go-

* Doutora em Ciências da Religião, professora do Programa de Pós-Graduação em Ciências da Religião da Universidade Metodista de São Paulo, e desde 2001, coordenadora do Grupo de Estudos de Gênero e Religião Mandrágora/Netmal e editora responsável pela revista Mandrágora. E-mail: sanduarte3@gmail.com 
als are many: to tell the story of the creation of NETMAL - Center for Theological Studies of Women in Latin America, in 1989, by initiative of students of the Graduate Program in Sciences of Religion; to point out the importance of the group for the presence and permanence of feminist professors in the Program; highlight its gender production in the form of theses and dissertations; and demonstrate that the oldest journal on gender and religion in Brazil is part of a long process of reflection and feminist action in the field of Religion Studies.. Keywords: Mandrágora; Feminist Studies; Gender; Science of Religion; Theology.

\section{MANDRÁGORA: LA HISTORIA DE UNA AUDAZ REVISTA FEMINISTA EN EL CAMPO DE LAS CIENCIAS DE LA RELIGIÓN Y LA TEOLOGÍA}

\section{RESUMEN}

El artículo presenta el contexto del surgimiento de Mandrágora, Revista de Estudios de Género y Religión del Programa de Posgrado en Ciencias de la Religión de la Universidad Metodista de São Paulo. Los objetivos son varios: contar la historia de la creación de NETMAL - Centro de Estudios Teológicos de la Mujer en América Latina, en 1989, por iniciativa de estudiantes del Programa de Posgrado en Ciencias de la Religión; señalar la importancia del grupo para la presencia y permanencia de las docentes feministas en el Programa; destacar la producción de género del Programa en forma de tesis y disertaciones; y demostrar que la revista de género y religión más antigua de Brasil es parte de un largo proceso de reflexión y acción feminista en el campo de los Estudios de Religión.

Palabras clave: Mandrágora; Estudios Feministas; Género; Ciencias de la Religión; Teología

\section{MANDRÁGORA/NETMAL: DA ALQUIMIA DE UM GRUPO DE PESQUISA}

A década de 1980 foi um período de grande efervescência e de novo ordenamento político no Brasil. A ditadura civil-militar perdeu força e iniciou-se o processo de reabertura política no país. Na década anterior, a Campanha pela Anistia Ampla, Geral e Irrestrita, já anunciava a falência do regime, mas é nos anos 1980 que as manifestações populares em favor de eleições diretas explicitam a crise do governo ditatorial, e apesar da não aprovação, pelo Parlamento, da Emenda Constitucional que visava restabelecer no país o direito ao voto para 
a presidência da República', as sementes da retomada da democracia estavam lançadas. As mobilizações que se seguiram na forma de passeatas e comícios envolvendo movimentos sociais, artistas, estudantes, intelectuais, lideranças políticas e religiosas, foram fundamentais para a derrocada do regime que cassou direitos e liberdades da sociedade brasileira. Em 1986 foram eleitos os/as parlamentares que participariam da Assembleia Nacional Constituinte, que redundaria na promulgação da nova Constituição em 1988.

No âmbito religioso, essa efervescência política provocou posicionamentos diversos, em especial nos grupos de tradição cristã. Verifica-se, por um lado, uma relação de cumplicidade com o poder ditatorial estabelecido e, por outro lado, a crítica a tal poder materializada, desde finais dos anos 1960, pela atuação das Comunidades Eclesiais de Base da Igreja Católica, alimentadas pela Teologia da Libertação e pelos movimentos da juventude protestante, dentre outros ${ }^{2}$. A narrativa histórica foi econômica no que tange à participação das mulheres cristãs nesse período, em especial em sua resistência à ditadura, e só recentemente, por força dos Estudos Feministas da Religião, essa atuação tem sido explicitada (Sandra Duarte de SOUZA, 2014).

Os anos 1980 também consolidam o movimento feminista no país. É nesse período que se verifica a ampliação da inserção de mulheres na academia. Novos grupos de estudo são criados e novas pesquisas são desenvolvidas, trazendo temas até então ignorados pela ciência, problematizando seus aparentemente sólidos paradigmas. A emergência de grupos de pesquisa como o NEM (Núcleo de Estudos da Mulher), na PUC-Rio33, criado em 1980; o NEIM (Núcleo de Estudos Interdisciplina-

Emenda Dante de Oliveira pelas “Diretas Já", votada em abril de 1984, data em que a ditadura no país completava 20 anos.

2 Sobre o apoio e a resistência de segmentos católicos e protestantes à ditadura, há várias publicações. Ver: Vasni ALMEIDA, 2009; Jeanne G. ARNOLD, 1983; Patrícia FACHIN, 2014; Arnaldo HUFF Jr., 2009; S. MAINWARING, 1989; Solange SIMÕES, 1985; Silas SOUZA, 2014; Sandra Duarte de SOUZA, 2014.

3 Interessante notar que o primeiro grupo de pesquisa desse tipo do qual se tem notícia foi criado em uma universidade confessional (comunitária). Anos depois as universidades públicas serão o principal terreno para o surgimento dos núcleos e grupos de pesquisa sobre mulheres e gênero. 
res sobre a Mulher), na UFBA em 1983; o NEPEM (Núcleo de Estudos e Pesquisas sobre a Mulher), na UFMG, em 1984; o NEMGE (Núcleo de Estudos e Pesquisas sobre a Mulher), na USP, em 1985, dentre outros, indica a intensa mobilização de acadêmicas para "ocuparem" a patriarcal universidade brasileira. Elas evidenciam a seletividade de uma academia acostumada a apresentar suas conclusões como universais e a ignorar os saberes e fazeres das mulheres. A explicitação das inconsistências e limitações dos modelos científicos e o questionamento das bases androcêntricas sobre as quais ele se assenta, provocaram o ambiente acadêmico e forçaram, literalmente, as portas das universidades para a entrada das mulheres e para o debate de gênero no país.

É nesse contexto que, em 1989, surge o NETMAL - Núcleo de Estudos Teológicos da Mulher na América Latina. O NETMAL é fruto da mobilização das estudantes do Programa de Pós-Graduação em Ciências da Religião, da Universidade Metodista de São Paulo, que, naquela época, eram mestrandas. É emblemático que, apesar das primeiras dissertações do PPG terem sido defendidas a partir de 1981, somente sete anos depois, em 1988, teremos uma dissertação defendida por mulher. Marilía Alves Schüller foi a primeira mulher a defender uma dissertação no Programa, e por muitos anos foi a única aluna negra do PPG. O trabalho de Marilía Schüller é um marco também porque se propõe a analisar uma revista voltada para mulheres cristãs "a partir da condição da mulher” (1988). Portanto, a primeira dissertação de mulher do PPG já indicava que estávamos chegando nas Ciências da Religião para colocar novas questões a esse hermético e androcêntrico campo de saber.

Ao final da década de 1980, mais mulheres ingressaram no Programa e se dedicaram a análises com foco em temas relativos a gênero, feminismo e religião. Foram elas, em especial as biblistas, que iniciaram os primeiros encontros daquilo que viria a ser o NETMAL e, mais tarde, o Mandrágora/Netmal ${ }^{4}$. As dissertações de Tânia Mara Sampaio

O nome do grupo passou a ser "Grupo de Estudos de Gênero e Religião - Mandrágora/Netmal”. A mudança se deu pelo fato do próprio grupo avaliar que o nome "Núcleo de Estudos Teológicos da Mulher na América Latina" já não comportava tudo aquilo que se pesquisava no Programa. Além disso, a crítica ao universal “mulher” também motivou a alteração. 
(1990) e Nancy Cardoso Pereira (1992) trouxeram novas questões para a hermenêutica bíblica, problematizando os Estudos de Religião em perspectiva feminista. É também de Tânia Mara Sampaio a primeira tese de doutorado defendida no Programa por uma mulher (1997). Esses e tantos outros trabalhos da área de concentração e, mais recentemente, da linha de pesquisa "Literatura e Religião no Mundo Bíblico", foram orientados pelo professor Milton Schwantes, que acompanhou 11 dissertações e oito teses de mulheres que envolviam análise de gênero5. As ações das primeiras mestrandas do programa também objetivavam a ampliação da participação das mulheres em todos os níveis de ensino e pesquisa, e foram voltadas, inclusive para a captação de recursos para a promoção de eventos voltados para comunidade em geral, participação em congressos, para dar suporte a mulheres que porventura precisassem de apoio, para produção e divulgação de subsídios para movimentos sociais e grupos religiosos e para reivindicar a contratação de uma docente especialista em Estudos Feministas e Religião.

A área/linha de "Literatura e Religião no Mundo Bíblico", apesar de ter formado muitas biblistas, algumas bem conhecidas, até há poucos anos teve exclusivamente homens como docentes e até o momento não tem nenhuma docente permanente. É sintomático também que nenhum PPG da área de Ciências da Religião e Teologia no Brasil tenha, em seu quadro docente, uma biblista egressa do Programa da Universidade Metodista. Elas são ativas em outras áreas de atuação, como a própria Tânia Mara Sampaio, que atualmente trabalha na área de Educação, Maria Aparecida Corrêa Custódio, que é docente na área de Sociologia, e Isabel Aparecida Felix, que trabalha com Pedagogia. Elas também lecionam em graduações e especializações em Teologia, como Haidi Jarschel, Mercedes Brancher, Elenira Aparecida Cunha, Marli Wandermuren, Maria Antônia Marques, Mariza Galvão, Mercedes Lopes, Francisca Rosa da Silva, Sue Hellen Monteiro de Matos e Elenira Aparecida Cunha; e dão assessoria a movimentos sociais e outros grupos, como Nancy Pereira Cardoso, Mercedes de Budallés Diez, Monika Ottermann e Floripes de Oliveira Reis.

Outros docentes da área/linha de Literatura Bíblica do PPGCR da UMESP também orientaram e orientam teses e dissertações que envolvem a análise de gênero, porém, Schwantes, falecido em 2012, ainda contabiliza o maior número de orientações sobre o tema na referida área. 
Algumas delas atuam em outros países na área de Teologia e afins, como Elvira Moisés da Silva Cazombo (Angola), Maricel Mena Lopes (Colômbia), Maria Cristina Ventura Campusano (Costa Rica). E há ainda biblistas que desempenham outros trabalhos, como Glória Maria Della Libera Pratas ou sobre as quais não encontramos notícias ${ }^{6}$, como a salvadorenha Ruth Evelyn Mauch, a peruana Hilda Dorotea Turpo Hancco, as brasileiras Benedita Pinto de Souza, Rita de Cássia Ló, Marli Lutz, Kellen Christiane Rodrigues de Araújo, Gabriela Dias de Oliveira Muniz.

Ao longo desses mais de 40 anos de existência do PPGCR da UMESP, essas mulheres, por meio de suas pesquisas e militância, denunciaram o androcentrismo da interpretação bíblica. O desejo de despatriarcalização das tradições interpretativas da Bíblia reuniu mulheres graduadas em Teologia para pesquisar e desenvolver ações diversas visando oferecer para a comunidade acadêmica, para grupos religiosos e para mulheres cristãs em geral, novas possibilidades de leitura e vivência do texto bíblico.

Mas a ênfase do NETMAL/Mandrágora não foi exclusivamente na área bíblica. As pesquisas da década de 1990 no Programa de Ciências da Religião eram também da área de Ciências Sociais e Religião, posteriormente absorvida pela área de Religião Sociedade e Cultura, e da área de Teologia e História, tendo sido a Teologia incorporada à área de Linguagens da Religião, e a História à área de Religião Sociedade e Cultura. Esta última área concentra o maior número de teses e dissertações sobre gênero defendidas no Programa. Em 1992, com a contratação da professora Maria José Fontelas Rosado Nunes, os Estudos Feministas da Religião no PPG ganham novo fôlego. Ela passa a coordenar o NETMAL, a promover eventos sobre feminismo e religião, a ministrar disciplinas voltadas para o debate de gênero e a orientar pesquisas nessa área. De 1992 a 2000, ano em que deixou o Programa7, Maria José Rosado Nunes orientou sete dissertações de mestrado e duas teses de doutorado de mulheres cujas pesquisas tinham como eixo principal as relações de gênero e religião ${ }^{8}$. Tratou-se do caráter generificado das instituições

Levantamento realizado na Plataforma Lattes e em sites de busca.

A professora é docente na PUC-SP.

Aqui estão elencadas exclusivamente as estudantes que pesquisaram sobre gênero e religião. 
religiosas, das experiências de gênero em contexto indígena, da sexualidade, dos direitos reprodutivos e do ecofeminismo.

Por reivindicação e mobilização das integrantes do NETMAL, foi criada a cátedra de Teologia Feminista, e em 1998, a professora Lieve Troch, nascida na Bélgica e docente na Holanda, passou a compor o corpo docente do Programa como professora colaboradora. Isso foi possível graças a uma parceria do PPG com a Igreja Reformada da Holanda que financiou as viagens e hospedagem da docente no Brasil. A atuação de Lieve Troch no NETMAL retomou o debate teológico no grupo. Além de ministrar aulas de Teologia Feminista e outras disciplinas, durante o período em que atuou no Programa a docente orientou ${ }^{9}$ quatro dissertações de mestrado e três teses de doutorado que tinham a teologia feminista como eixo principal, e que trataram de mulheres no candomblé, teologia do corpo e hermenêutica feminista. Ela também foi uma das editoras responsáveis pela revista Mandrágora. Com a aposentadoria da professora Lieve Troch, a cátedra foi desativada, apesar dos esforços e tentativas de negociação do Mandrágora/Netmal e do PPG junto à Igreja Reformada para a continuidade do financiamento para a contratação de nova docente para a área, preferencialmente uma teóloga feminista brasileira. Esse é um desafio que se coloca para o grupo e para o PPG em Ciências da Religião da Universidade Metodista, pois a área carece de docentes nesse campo.

No ano 2001 eu assumi a vaga de Gênero e Religião que foi aberta com a saída da professora Maria José Rosado Nunes, de quem fui orientanda. Manter essa linha de pesquisa foi a reivindicação do Mandrágora/ NETMAL e a proposta foi acolhida pelo Programa. Esse foi o segundo concurso público realizado pelo PPGCR ${ }^{10}$. Os desafios foram muitos: coordenar o grupo do qual fiz parte como estudante desde 1993; ser a editora responsável pela revista Mandrágora; ministrar aulas sobre gênero, feminismo e religião e orientar pesquisas nesse campo, den-

9 Os números aqui não incluem os homens (mestrandos e doutorandos) que também foram orientados pela docente.

10 O primeiro foi realizado um semestre antes para uma vaga na área de Pastoral. Antes disso não havia concurso para a composição do corpo docente. A história dessa minha "chegada" ao PPG precisa ser contada em outro momento. 
tre outras atribuições. Até o momento, foram defendidas sob a minha orientação, 26 dissertações de mestrado e cinco teses de doutorado escritas por mulheres e que tratam de gênero e religião em diversas perspectivas ${ }^{11}$. São trabalhos que analisam o catolicismo, o protestantismo, os pentecostalismos, as religiões afro-brasileiras, o Islã, o budismo, o trânsito religioso, a política e as questões de gênero que envolvem expressões religiosas em sua forma institucionalizada ou não. É claro que eu e as docentes aqui mencionadas também orientamos dissertações e teses sobre gênero escritas por homens, mas optei por contabilizar as orientações de mulheres para destacar a importância dessa atuação na formação de pesquisadoras e professoras para a área.

Todo esse trabalho tem sido possível porque há 32 anos aquele grupo de mulheres não se conformou com o não reconhecimento acadêmico das mulheres como sujeitos epistêmicos. O trabalho coletivo do Mandrágora/Netmal tem sido fundamental para o debate interno e externo sobre feminismo, gênero e religião, e ele está presente em diferentes fóruns de debate, seja na academia, em movimentos sociais, na mídia ou em grupos religiosos diversos, transformando tudo aquilo que toca, num processo alquímico singular.

A revista Mandrágora nasce com o intuito de registrar e fazer visível aquilo sobre o que o patriarcal universo dos Estudos de Religião silenciava. Como escreveu Maria José Rosado Nunes na apresentação do primeiro número da revista, "como a planta que lhe dá nome, mista de doçura e veneno, MANDRÁGORA chega para enfeitiçar, inebriante e mágica, capaz de vencer a esterilidade e provocar novas gestações" (1994, p. 5)

\section{REVISTA MANDRÁGORA: AS BOAS NOVAS FEMINISTAS NO CAMPO DAS CIÊNCIAS DA RELIGIÃO E TEOLOGIA}

Foi sob a coordenação de Maria José Rosado Nunes que o NETMAL decidiu criar uma publicação que pudesse sistematizar as discussões realizadas nas suas reuniões, nas salas de aula e nos seminários organizados anualmente pelo grupo. É assim que, em 1994, foi publicada a revista

\footnotetext{
Aqui também utilizei o mesmo critério e só enumerei mulheres que tiveram como eixo de pesquisa a articulação entre gênero e religião.
} 
Mandrágora, o primeiro e, por muitos anos ${ }^{12}$, o único periódico do país a ter como eixo temático a relação entre feminismo, gênero e religião ${ }^{13}$.

O nome da revista foi gerado no grupo, nos idos anos 1990, e quer traduzir os sentidos de ser mulher e se trabalhar gênero no masculino mundo dos Estudos de Religião. Mandrágora é uma planta cuja raiz lembra o corpo de uma mulher. Em sua introdução ao primeiro número da revista, Nancy Cardoso Pereira lembra que a planta era utilizada como remédio e veneno e afirma:

Sabemos que nossa memória e tradição como teólogas e cientistas da religião muitas vezes foram guardadas e escondidas por mulheres feiticeiras, benzedeiras, santas, cozinheiras, amantes, gozosas, devotas, lutadoras, criadoras de caso, criadoras de vida. Nos juntamos a elas. Nossa herança são estas raízes carnudas na forma do corpo, estas flores púrpuras e pequenas frutas. (1994, p. 6)

A Mandrágora nasce para fazer brotar do árido solo da academia os saberes e fazeres das mulheres. A revista não se restringe à publicação de mulheres, mas a própria escassez de espaços onde mulheres que estudam religião e gênero, ou feminismo e religião possam publicar, termina fazendo com que elas sejam suas articulistas mais frequentes.

Todas as editoras da revista, desde o seu início, são mulheres, o que tem possibilitado a formação também nesse campo. É importante ressaltar, porém, que todas as decisões sobre os temas e sobre os encaminhamentos da revista, são tomadas coletivamente, em reuniões periódicas do grupo de pesquisa, o que possibilita a participação efetiva de todas as pessoas do grupo. A Mandrágora teve como coordenadoras editoriais duas mulheres da área de Literatura no Mundo Bíblico - Haidi Jarschel e Nancy Cardoso Pereira - e uma mulher da área de Comunicação Social - Mara Regina Vidal. Em 1996, Cecília Castilho Nanjarí, da área de Teologia e História e eu, Sandra Duarte de Souza, da área de Ciências Sociais e Religião, nos somamos à coordenação editorial da revista. Ao longo dos anos a equipe editorial recebeu a contribuição de várias mulheres - Eurides Alves Oliveira, Fernanda Lemos, Raquel

12 A revista Coisas do Gênero do PPG em Teologia da EST foi criada em 2015.

13 Até 2014 a publicação era anual. A partir de 2015, a Mandrágora passou a ser publicada semestralmente. 
Carmem Riquelme, Ana Carolina Alves e Lieve Troch - que trabalharam incansavelmente na revista. A professora Lieve Troch, como mencionamos anteriormente, também foi uma das editoras responsáveis pela Mandrágora. A sazonalidade na equipe se dá pelo fato da conclusão dos estudos das mestrandas e doutorandas no PPG, que terminam se dedicando a outras atividades profissionais e não conseguem permanecer na editoria da revista. Atualmente, eu respondo como editora responsável pela revista, e a comissão editorial é composta pelas professoras Clarissa de Franco, que assumiu como docente do PPG em 2021 e se soma a nós na coordenação do GP, Naira Pinheiro dos Santos, Nirvana de Oliveira Moraes Galvão de França e Tainah Biela Dias, todas da área de Religião, Sociedade e Cultura. Mais uma vez fica explícita a necessidade de reativarmos a cátedra de Teologia Feminista e oferecermos no Programa a necessária formação e pesquisa voltada para a Teologia e a Hermenêutica Bíblica Feminista. No momento ampliamos a participação de teólogas feministas no grupo de pesquisa, oferecemos disciplinas que dialogam com a produção teológica feminista, e alguns novos trabalhos nessa área estão em andamento por mestrandas do PPG, porém, é preciso muito mais.

Quanto aos conteúdos, inicialmente a Mandrágora se estruturou a partir de temas específicos ${ }^{14}$, e posteriormente passou a publicar dossiês e artigos diversos desde que articulassem gênero/feminismo e religião. Os números temáticos foram os seguintes: Direitos Reprodutivos e Aborto (1994); Estudos Feministas e Cristianismo (1995); Gênero, Cultura e Religião (1996); Direitos Reprodutivos, Religião e Ética (1997); Religião e Homossexualidade (1999); Ecofeminismo: tendências e debates (2000); História, Gênero e Religião / Violência, Gênero e Religião (2001/2002); Gênero, Religião e Modernidade (2004); O Imaginário Feminino da Divindade (2005); Gênero, Religião e Políticas Públicas (2007); Gênero, Fundamentalismo e Religião (2008); Gênero e Religião nas Artes (2009); Cor-po e coloração: reflexões na área de gênero e religião (2010); Religião e Sexualidade (2012); Religião e Perspectivas Históricas (2013); Homenagem a Ivone Gebara (2014).

14 Até 2014 a revista manteve esse padrão, com exceção dos números de 2003 e 2011, que foram organizados a partir de artigos com temas diversos. 
A coragem de tematizar os direitos reprodutivos, a sexualidade, a violência de gênero e tantos outros aspectos tabus nos Estudos de Religião, descortinou um universo amplo a ser pesquisado na área. A partir de 2015, para ampliar a presença dos Estudos Feministas da Religião na academia brasileira, a Mandrágora passou a ser publicada semestralmente. Mais um desafio, uma vez que todo o trabalho da revista é realizado de forma voluntária. Desde então, sem nunca perder a periodicidade, já publicamos dezenas de artigos sobre gênero, feminismo e religião. Os dossiês discutem direitos humanos, violência de gênero, religião e política, educação e o mais recente (1/2021) é uma "mulheragem" à professora Maria José Rosado Nunes, nossa querida Zeca, por sua trajetória no campo dos estudos e da militância feminista.

Mandrágora, essa mulher madura de 27 anos é, indiscutivelmente, uma referência na área de Ciências da Religião e Teologia quando o assunto é Gênero e Religião. Os temas mais recorrentes nas pesquisas de gênero da área revelam uma insistência de pesquisadoras e pesquisadores em ampliar os tradicionais campos de interesse das Ciências da Religião e Teologia. Qualquer trabalho que deseje levantar aquilo que se tematiza sobre gênero na área, não pode se furtar a entrar nas páginas dessa longeva revista que se confunde com a própria história da constituição do campo de Estudos de Gênero e Religião no Brasil.

Vida longa à Mandrágora!

\section{REFERÊNCIAS}

ALMEIDA, Vasni de. Os metodistas e o golpe militar de 1964. Estudos de Religião. Vol. 23, no. 37. São Bernardo do Campo: Universidade Metodista de São Paulo, pp. 57-68, jul-dez 2009.

ARNOLD, Jeanne Gosselin. A Man of Faith - Father Patrick Peyton, CSC, his life, mission and message. Family Theater, Inc. Hollywood, California, 1983.

FACHIN, Patrícia. As Marchas da Família com Deus pela Liberdade 50 anos depois. Entrevista especial com Aline Pressot. IHU-UNISINOS, março de 2014. Disponível em $<$ http://www.ihu.unisinos.br/entrevistas/529378-cinquentenario-da-marcha-com-deus-pela-familia-e-a-liberdade-e-uma-sociedade-que-nao-se-reconciliou-com-a-memoria-da-ditadura-entrevista-especial-com-aline-pressot- >. Acesso em 10 set. 2021.

HUFF Jr., Arnaldo Érico. Richard Shaull pelo ecumenismo brasileiro: um estudo acerca da produção da memória religiosa. Revista Brasileira de História das Religiões, ano II, 
no. 4, pp. 3-19, Maio de 2009. Disponível em <http://www.dhi.uem.br/gtreligiao/pdf3/ texto1.pdf >. Acesso em 03 set. 2021.

JARSCHEL, Haidi. Gênesis 25 a 36: Cotidiano Transfigurado. Dissertação de Mestrado em Ciências da Religião. São Bernardo do Campo: Universidade Metodista de São Paulo, 1994.

MAINWARING, S. Igreja Católica e política no Brasil - 1916-1985. São Paulo: Brasiliense, 1989.

NUNES, Maria José F. Rosado. Mandrágora. Revista Mandrágora, ano 1, no. 1. São Bernardo do Campo: Universidade Metodista, 1994, p. 5.

PEREIRA, Nancy Cardoso. Profecia e Cotidiano. Dissertação de Mestrado em Ciências da Religião. São Bernardo do Campo: Universidade Metodista de São Paulo, 1992.

PEREIRA, Nancy Cardoso. Mandrágora. Revista Mandrágora, ano 1, no. 1. São Bernardo do Campo: Universidade Metodista, 1994, p. 6.

SAMPAIO, Tânia Mara. Mulher: Uma Prioridade Profética em Oséias. Dissertação de Mestrado em Ciências da Religião. São Bernardo do Campo: Universidade Metodista de São Paulo, 1990.

SAMPAIO, Tânia Mara Vieira. Movimentos do corpo prostituído da mulher na beleza do cotidiano. Uma aproximação da profecia atribuída a Oséias. Tese de Mestrado em Ciências da Religião. São Bernardo do Campo: Universidade Metodista de São Paulo, 1997.

SCHÜLLER, Marilía Alves. Revista Voz Missionária - 1981 a 1985: Uma Análise de Conteúdos a Partir da Condição da Mulher. Dissertação de Mestrado em Ciências da Religião. São Bernardo do Campo: Universidade Metodista de São Paulo, 1988.

SIMÕES, Solange. Deus, Pátria e Família: as mulheres no golpe de 1964. Petrópolis, Vozes, 1985.

SOUZA, Sandra Duarte de. Ditadura militar brasileira: a propósito da agência política de mulheres cristãs. In: SOUZA, Sandra Duarte de e SANTOS, Naira Pinheiro dos. Estudos Feministas e Religião: tendências e debates. Curitiba: Prismas, 2014, p. 149-171.

SOUZA, Silas Luíz. Protestantismo \& Ditadura: Presbiterianos e o governo militar no Brasil - 1964-1985. São Paulo: Fonte Editorial, 2014.

Submetido em: 9-9-2021

Aceito em: 13-12-2021 